\title{
Anthropogenic forcing of fish boldness and its impacts on ecosystem structure
}

\author{
Wang, Wei; Xu, Nuo; Zhang, Lai; Andersen, Ken H.; Klaminder, Jonatan
}

Published in:

Global Change Biology

Link to article, DOI:

$10.1111 / \mathrm{gcb} .15473$

Publication date:

2021

Document Version

Peer reviewed version

Link back to DTU Orbit

Citation (APA):

Wang, W., Xu, N., Zhang, L., Andersen, K. H., \& Klaminder, J. (2021). Anthropogenic forcing of fish boldness and its impacts on ecosystem structure. Global Change Biology, 27(6), 1239-1249.

https://doi.org/10.1111/gcb.15473

\section{General rights}

Copyright and moral rights for the publications made accessible in the public portal are retained by the authors and/or other copyright owners and it is a condition of accessing publications that users recognise and abide by the legal requirements associated with these rights.

- Users may download and print one copy of any publication from the public portal for the purpose of private study or research.

- You may not further distribute the material or use it for any profit-making activity or commercial gain

- You may freely distribute the URL identifying the publication in the public portal

If you believe that this document breaches copyright please contact us providing details, and we will remove access to the work immediately and investigate your claim. 
PROF. LAI ZHANG (Orcid ID : 0000-0003-2409-7348)

Article type : Primary Research Articles

Title: Anthropogenic forcing of fish boldness and its impacts on ecosystem structure

Running title: Boldness change affects ecosystem structure

\section{List of authors:}

Wei Wang ${ }^{1, \#}$, Nuo Xu ${ }^{1, \#}$, Lai Zhang ${ }^{1, \dagger}$, Ken H. Andersen², Jonatan Klaminder ${ }^{3}$

${ }^{1}$ School of Mathematical Science, Yangzhou University, Yangzhou 225002 China

${ }^{2}$ Center for Ocean Life, National Institute of Aquatic Resources, Technical University of

Denmark, Denmark

${ }^{3}$ Department of Ecology and Environmental Science, Umeå University, Umeå, Sweden

Corresponding author:

Email: lai.zhang@yzu.edu.cn

Tel: +86051487975406

ORCID ID: 0000-0003-2409-7348

\#Wei Wang and Nuo Xu should be considered joint first author.

Abstract: Modified fish behaviors in response to anthropogenic stressors, such as chemicals, microplastics, acoustic emissions and fisheries, are a debated driver of change in freshwater

This article has been accepted for publication and undergone full peer review but has not been through the copyediting, typesetting, pagination and proofreading process, which may lead to differences between this version and the Version of Record. Please cite this article as doi: $10.1111 / \mathrm{gcb} .15473$

This article is protected by copyright. All rights reserved 
ecosystems and oceans. Our ability to judge the severity of observed behavioral responses is hampered by limited knowledge regarding how subtle behavior modifications in prey fish affect ecosystems. Here we show that anthropogenic stressors affecting fish boldness, are not expected to cause population collapse, but rather elusive effects on fish length, population biomass, reproduction and ecosystem state shifts. We use a physiologically structured population model (three trophic levels), well fed with empirical data, to simulate how previously suggested alterations of fish boldness traits due to anthropogenic stressors affect ecosystem structure. Our results suggest that these stressors may cause ecosystem structure effects, such as skewed size distributions, reduced fish biomass and reduced reproduction success, by altering the foraging behavior of fish. However, the specific structure effects depend on where the boldness-shyness continuum change occurs and on the species-specific life-stages. The model also highlights somewhat counterintuitive effects leading to possible extinction of predators when the foraging behavior of the prey is hampered. We conclude that anthropogenic forcing of fish behavior may be a hidden mechanism behind ecosystem structure changes in both freshwater and marine ecosystems.

Keywords: behavioral trait, boldness alteration, life history, aquatic ecosystem, size-structured population model, regime shift 


\section{Introduction}

Since the onset of modern environmental science in the 1970s, it has been recognized that chemical stressors can alter the behavior of fish, but that the implications of these non-lethal behavioral modifications are difficult to predict (Sprague, 1971), a notion that still lingers within modern ecotoxicology (Johnson et al., 2020; Tanoue et al., 2019). Still, alteration of fish behavior due to contaminant exposure has been identified as a potential driver of ecosystem change (Brodin et al., 2014). Fish behaviors are not only changing in response to traditional metal pollutants, but also in response to a variety of anthropogenic stressors such as microplastics (McCormick et al., 2020), other emerging contaminants (Brodin et al., 2013; Dzieweczynski et al., 2016; Lagesson et al., 2018b; Vignet et al., 2015), elevated temperature (Biro et al., 2010; Briffa et al., 2013; Závorka et al., 2020), acidification (Nilsson et al., 2012), acoustic emissions (Mills et al., 2020; McCormick et al., 2018; Nedelec et al., 2017; Sabet et al., 2015), release of hatchery reared individuals (Roberts et al., 2011) and selective harvesting of bold and more exploratory individuals (Biro \& Post, 2008). While various forms of fish and behavioral trials have been used in these studies, they all have in common that they show that anthropogenic stressors can affect fish's boldness (Fig. 1), a personality trait that affects predation risk and therefore fitness (Lind \& Cresswell 2005; Smith \& Blumstein 2008).

Boldness is believed to be directly linked to foraging rates (positively) and predator avoidance (negatively), and thus has high predictive power for ecological and evolutionary outcomes in nature (Réale et al., 2007). While direct toxic effects of a stressor are easy to grasp from an ecological perspective, effects caused by altered fish boldness in an ecosystem with several trophic levels is less straightforward. For example, contaminant improved boldness can have positive effects on foraging and fish survival when predators are absent (Klaminder et al., 2014), but these seemingly beneficial behavioral changes can increase predation losses in natural settings (Klaminder et al., 2019). The current knowledge gap regarding how anthropogenic driven changes in fish boldness and the implicit change in foraging behavior may affect ecosystem structure limits our ability to judge the severity of behavioral change in aquatic environments. This knowledge gap also limits our ability to detect early warning signs in environmental 
monitoring programs indicating fish behavioral changes in response to anthropogenic stressors.

According to ecological theory, increased boldness will not only improve foraging and growth but also increase predation losses (Réale et al., 2007). However, increased fish boldness has been linked both to positive impacts (Biro \& Post, 2008) as well as negative impacts (Adriaenssens \& Johnsson, 2011) on fish growth and survival. Clearly, contrasting effects on growth and survival from boldness measures create uncertainty regarding how this trait impacts wild fish populations. Ecosystem structure models, particularly when supported with empirical data, can be greatly helpful in foreseeing how boldness effects may cascade through ecosystems. In this study, we conduct the first population modelling effort describing how increased boldness (expressed as increased foraging) among fish alters ecosystem structure; hence, information that is necessary for detecting early warning signs of ecosystem changes due to behavior modifications when using data from ongoing environmental monitoring programs. Here, we scrutinize a predator-prey system with Eurasian perch (Perca fluviatilis) and roach (Rutilus rutilus) populations, representing a system suggested to be affected by boldness modifications due to angling (Härkönen et al., 2016) and environmental relevant levels of anxiolytics entering freshwater ecosystems via effluent waters (Brodin et al., 2013, 2017). We use a well-studied perch-roach system, for which an empirically validated population model exists (de Roos \& Persson, 2002). Using this state-of-the-art model, including a boldness dependent shift in foraging rate, we test the hypotheses that increased boldness in juvenile of roach can cause substantial impacts on: i) population size structure; and ii) regime shift in the predator-prey system.

\section{Methods}

The model is parameterized to describe the life history of the planktivorous fish (roach) feeding on a resource species (zooplankton) and being predated by the piscivorous fish (adult perch) in a simple lake system (de Roos \& Persson, 2002). We take feeding, growth, reproduction and mortality rate as indices to describe the life history of the consumer individuals, which are determined by their length $x$, the resource biomass $R$, and predator population density $P$. Model dynamics are described by the following set of differential equations 


$$
\begin{aligned}
& \frac{\partial c(t, x)}{\partial t}+\frac{\partial g(R, x) c(t, x)}{\partial x}=-\mu(x, R, P) c(t, x), \\
& g\left(R, x_{b}\right) c\left(t, x_{b}\right)=\int_{x_{j}}^{x_{m}} b(R, x) c(t, x) d x \\
& \frac{d R}{d t}=r(K-R)-\int_{x_{b}}^{x_{m}} \frac{\tau A(x) R}{1+\tau A(x) H(x)} c(t, x) d x, \\
& \frac{d P}{d t}=\left(\varepsilon \frac{\tau a B}{1+\tau a T_{h} B}-\delta\right) P
\end{aligned}
$$

where the first two equations describe the density dynamics and recruitment flux of the consumer population. The symbol $c(t, x)$ denotes the consumer density of body length $x$ at time $t$ (units of numbers per length), and $g(R, x), \mu(x, R, P), b(R, x)$ are the rates of consumer growth, mortality and reproduction. Consumer individuals are born at length $x_{b}$, mature at length $x_{j}$ and grow to the maximally attainable length $x_{m}$ provided they have sufficient food. The third equation describes resource biomass dynamics, which follows semi-chemostat growth and is foraged by the consumers of all lengths. The last equation describes predator density dynamics of the Lotka-Volterra type, where the predator feeds on the biomass $B$ of consumers of body size between $x_{b}$ and $x_{m}$ (Table 1, Equation N2), and at the same time experiences a constant background mortality rate $\delta$. The feeding follows the type II functional response with an attack rate $a$ and a handling time $T_{h}$, and the food is assimilated with a conversion efficiency $\varepsilon$ (de Roos \& Persson, 2002). The life-history forms of the consumer are listed in Table 1, and model variables and parameters are summarized in Table 2. Detailed model description is given as follows.

Consumers acquire energy from the resource at a rate $F(x, R)$ (Equation $\mathrm{N} 6$ ), where $A(x)$ is the size-dependent attack rate, a dome-shaped function peaking at the body size $w_{\text {opt }}$ (Equation N5). Individual's body mass is assumed to be proportional to its cubed body length (Equation N1). $H(x)$ is the digestion time, an allometric function of the body size (Equation N3), which is limited by the capacity of gut to process food. The encountered food is assimilated with an efficiency $\varepsilon_{R}$, and the assimilated energy is then utilized by maintenance, growth and reproduction, of which a fraction $\kappa$ is allocated to growth and maintenance, and the remaining to gonad development for immature individuals or to offspring reproduction for mature individuals (Kooijman, 1993). 
Maintenance takes precedence over growth, and consists of basal and active metabolic costs (Equation N4), which are of the similar allometric form (Andersen et al., 2018). The surplus energy after paying metabolic costs is then used for individual growth (Equation N7), but growth ceases if metabolic costs are not met. Reproduction occurs for mature individuals with an efficiency $c_{r}$, and the birth rate is derived by calculating the energy cost of every single egg (Equation N8). Mortality rate (Equation N9) is composed of background mortality $\mu_{0}$, starvation mortality $\mu_{s}$, and predation mortality $\mu_{p}$. All consumer individuals suffer from a size-independent background mortality and may further experience a starvation mortality when energy is insufficient for metabolic costs (Equation N10). Consumers are under the risk of being foraged, but only for individuals of length between $x_{b}$ and a threshold $x_{v}$ (Equation N11; de Roos \& Persson, 2002).

We introduce a boldness trait for consumer individuals in our model. The boldness trait is described by the boldness parameter $\tau$, ranging from 0 to 1 , where higher values imply increased boldness. Fig. 2a show examples of how $\tau$ varies in response to chemical stressors when boldness scores are inferred from the time $\left(t_{1}\right)$ spent in an area with increased perceived risk (novel object inspection, scototaxis or movements outside the thigmotaxis zone) during the observational period $(t)$ or the inverse of latency $\left(t_{2}\right)$ to enter such area, i.e. boldness is expressed in the figure as $\mathrm{t}_{1} / \mathrm{t}$ or $1-\mathrm{t}_{2} / \mathrm{t}$.

For the chemical induced boldness alterations illustrated in Fig. 2a, only the study by Brodin et al. (2013) directly quantified how the increased boldness increased the foraging rate (Fig. 2b). Therefore, we used the boldness-induced shift in foraging rate in the exposure oxazepam treatment of Brodin et al. (2013) in our model as being representative of a chemical altered boldness $(\Delta \tau)$. Note that the chemically altered boldness, driving the shift in foraging, seems representative also for many other chemical stressors (Fig. 2a). Constraining $\tau$ based on the foraging data from Brodin et al. (2013) also seems rationale considering that foraging rate by the study organism (Perch) is often used as a good measure of boldness (Magnhagen \& Borcherding, 2008). Increased boldness in our model leads to increased foraging which trades off with increased metabolic costs and increased vulnerability to predation. These are accounted for by 
multiplying the maximal attack rate, the active metabolic costs and the attack rate of predator with boldness $\tau$. Therefore, when fish show freezing behavior or hiding in a predator free refuge $(\tau=0)$, there is neither food intake nor active metabolism (only basal metabolism), but also no predation mortality (only background mortality and starvation mortality). In the present work, we primarily focus on boldness alteration in juvenile consumers while keeping behaviors of the predator and resource species unchanged. This is because the juvenile consumers are the key target for predators in the system and increased predation of juvenile fish as they become bolder has been argued to be the key driver of fish population collapse (Munday et al., 2010). Sensitive analysis with respect to the allometric constant $\left(\rho_{f}\right)$ (Appendix S1) and exponent $\left(\rho_{2}\right)$ (Appendix S2) of the active metabolism (N4), and model variants including boldness change for all consumers regardless of their sizes (Appendix S3) or the absence of the predator (Appendix S4) are explored but presented in the Supporting Information.

We start with a pristine environment that is free from anthropogenic stressors and assume that all consumers regardless of their body sizes are of the same boldness level. To ensure the coexistence of the three species, the minimal boldness level for consumers is $\tau^{*}=0.38$, which is interestingly coincident with mean boldness level of fish under control state in Fig. 2. To explore how anthropogenic stressors induced boldness change in juvenile consumers affects ecosystem structure, we then increase the boldness of juvenile consumers from the critical boldness level $\tau^{*}$ to 1 while keeping the boldness of adult consumers at $\tau^{*}$. Nonetheless, a different threshold value $\tau^{*}=0.5$ was also tested for assessing robustness of our findings (Appendix S5). The validity of our model was tested by comparing modeled mortality rates with measured mortality in studies where $\Delta \tau$ was generated using the same chemical stressor (oxazepam) driving our model (Appendix S6). In short, our model was able to correctly foresee observe reduced mortality rates for two-year old fish (perch) in a predator free environment (Klaminder et al., 2014) as well as increased mortality for two-year old fish (Salmo salar) in a natural setting with predators (Klaminder et al., 2019).

\section{Results}

A shift in boldness (i.e. $\Delta \tau$ ) of the same magnitude as that suggested to occur in response of many 
chemical stressors (Fig. 2), have substantial impact on ecosystem structure. In short, we predict boldness driven effects on ecosystem biomass (Fig. 3), body length (Fig. 4), population reproduction (Fig. 5a), and individual growth rate (Fig. 5b) of the consumer species roach. Fig. 3 demonstrates the bifurcation diagram along the timidity-boldness axis in terms of equilibrium biomass. With increasing boldness for consumer juveniles, the three species can always coexist, but the system responds to boldness changes by passing through multiple steady states before entering a single steady-state. In case of alternative steady states, the high and low biomass states are stable and the intermediate biomass state is unstable. The bistability range is considerable over a range of $\tau(0.38 \leq \tau \leq 0.5)$, which is well within the range affected by boldness changes caused by anthropogenic stressors (Fig. 2). While our model does not suggest a expiration of juveniles as their boldness increased, we notice that the predator cannot coexist with consumers if they greatly reduce their boldness and cause a steady state with low biomass. Moreover, the predator biomass responds negatively to increased boldness of juveniles as the prey biomass becomes reduced, an effect so far not recognized when predicting the ecological consequences of anthropogenic induced boldness.

Although there is a rapid increase in the biomass of adult consumer with lower boldness (Fig. 3b), the offset between biomass of juveniles (Fig. 3c) and adults leads to an overall decline of total fish biomass, compared to the biomass when predator is just able to invade (i.e. $\tau=\tau^{*}$, Fig. 3a). Our model suggests that increased boldness can further promote the average length of adult individuals and the maximum length of consumers, increasing by about $40 \% \sim 50 \%$. In contrast, the bolder juveniles are, the shorter the average length of juveniles becomes. Juveniles who spend a larger fraction of time foraging can be $40 \%$ shorter than individuals who live under the threshold invasion level of predator. In other words, our model suggests that increased boldness of juveniles promotes adult growth, but not necessarily juvenile growth in particular when $\tau>0.5$, although juveniles may have larger food intake due to longer foraging time. The reason could be that while juveniles spend more time searching for prey, the increased metabolic costs partly counteract the benefits of foraging. The faster growth rate of adults is due to the increased resource biomass (Fig. 3d) and reduced resource competition with juveniles. Hence, increasing 
boldness significantly promotes adult growth but depresses juvenile development. The descending average length of juveniles counterbalances the ascending of adults and further decreases the average length of consumers comprehensively. It is worth mentioning that the modeled boldness induced changes in ecosystem properties and population structures are fairly robust when different allometric constant $\left(\rho_{f}\right)$ and exponent $\left(\rho_{2}\right)$ in the active metabolism were adopted (Appendix S1 and S2).

Mechanisms behind the observed effects on biomass and size are revealed when probing reproduction and growth rate as a function of boldness (Fig. 5). The relative reproduction increases rapidly for a small increase in boldness, but drops down steadily as boldness is further elevated (Fig. 5a). The improved reproduction $(0.38 \leq \tau \leq 0.5)$ together with the improved growth rates (Fig. 5b) serves as an explanation for a boldness-driven increase in adult biomass (Fig. 4a). Here, the decline in reproduction $(0.5>\tau)$ explains the substantial decrease of juvenile and adult biomass (Fig. 4a). Our model suggests that response to boldness may depend both on where the boldness-shyness continuum change occurs and on the species-specific life-stages.

\section{Discussion}

\section{Anthropogenic induced boldness as a driver of freshwater ecosystem structure}

That boldness traits can affect individual life histories such as fast growth and maturation is well known (Biro \& Stamps, 2008; Jørgensen \& Holt, 2013; Réale et al., 2010). Nevertheless, our work presents the first life-history model in a multiple species context at an ecosystem level and reveals how anthropogenic stressors that modify fish boldness is expected to change ecosystem structure. Implicit in our findings is that anthropogenic forcing of boldness traits may not necessarily cause extinction of species, effects that are fairly easily detected in environmental monitoring programs, but rather elusive effects acting on length distribution and population biomass.

Previous studies have argued that perch-roach ecosystems may experience increased fish boldness in response to pharmaceutical contaminants (Brodin et al., 2013, 2017; Klaminder et al., 2014) or drift towards more shy populations due to angling (Härkönen et al., 2016). Initial 
attempts to quantify impacts of increased boldness induced by pharmaceuticals (oxazepam) in a multi-species environment with juvenile perch and a predator (pike) show a slight increased juvenile biomass and mortality in line with our model output, but the effects were not statistically significant (Lagesson et al., 2018a). Our model illustrates the difficulties in detecting such short-term effects as these effects are expected to be small until the boldness forcing passes a tipping point where an ecosystem stage-shift occurs.

Restocking natural populations with hatchery reared fish serves as an additional mechanism in which human activities alter fish population boldness and thus, generate a change that our model predicts will have cascading implications for population and community dynamics. Empirical evidence shows that hatchery-reared juveniles of wild salmon (Salmo salar) are bolder and less responsive to predators than their wild counterparts (Jackson \& Brown, 2011), and a similar observation was found in stickleback fish (Gasterosteus aculeatus) (Wund et al., 2015); hence, by restocking wild populations with hatchery reared fish there is an anthropogenic forcing towards bolder fish. Our model suggests that such management actions may directly alter population life-histories (Fig. 5) and subsequently reshape population structure (Fig. 4). Furthermore, by introducing bolder individuals from hatcheries managers of freshwater may facilitate establishment of invasive predators that were unable to remain when solely wild and shy populations were present (Fig. 3). However, even in the absence of predators, we found that improved boldness for juvenile consumers can also bring about considerable changes in population structure, particularly for adults including depressing growths. The reason is that boldness change greatly magnifies the intraspecific resource competition between juveniles and adults (Appendix S3).

One intriguing finding is that while a small increase in boldness for juvenile consumers benefits population reproduction, a large increase in boldness could lead to a substantial decline in population reproduction (Fig. 5a). This finding is not entirely consistent with previous observations suggesting that increased boldness contributes to high population reproduction (Biro \& Stamps, 2008; Walsh et al., 2006). This difference is likely due to the presence of predators in our model in contrast to previous studies. We did observe positive correlation between boldness 
improvement and population reproduction in the absence of predators (Appendix S3). These apparently contrasting observations warn that caution must be taken when drawing conclusion on how behavioral changes affect population life histories from laboratory studies that cannot virtually mimic natural conditions for instance replacing predator species by predator cues. In addition, existing empirical studies showed positive correlation between boldness and growth (Øverli et al., 2006; Ward et al., 2004). Our results demonstrated that boldness improvement for juveniles did not necessarily lead to fast growth themselves, but instead indirectly resulted in faster growth of the adult population due to high predation mortality for juveniles, which relieved intraspecific resource competition, a result suggesting the important role of indirect feedback of behavioral change on density-dependent life-history trade-offs.

But is there any empirical support that could indicate that freshwater ecosystems show signs of being influenced by increased fish boldness over a longer-time scale in line with our predictions? The most striking similarity between our model simulations and empirical data is ecosystem structure effects in perch-roach systems attributed to acidification of freshwater lakes. That is, reduced juvenile biomass, reduced reproduction success and skewed perch length distributions are typically observed for perch populations in lakes experiencing acidification (Lappalainen et al., 1988; Muniz, 1984). Historically, effects of acidification have mainly been explained by direct toxic effects on roe, resources and fish (Appelberg et al., 1993). While we do not question the importance of these previously recognized drivers of ecosystem change, our work indicates that acidification-induced boldness may be an additional, but unconsidered mechanism, behind ecosystem structure change in acidified lakes. In acidified lakes, the increased boldness is expected to be caused both by a reduced anti-predator behavior due to less efficient detection of olfactory cues at low pHs values (Brown et al., 2012) as well as identified neurological effect causing an anti-anxiety like effect in fish (Chivers et al., 2014; Nilsson et al., 2012).

\section{Anthropogenic induced boldness and its effects in marine ecosystems}

While our model results reproduce ecosystem structure effects in acidified freshwater, it is worth mentioning that the previously suggested increase in fish boldness in response to minor $\mathrm{pH}$ drop 
(about $0.5 \mathrm{pH}$ units) in global oceans due to rising atmospheric $\mathrm{CO}_{2}$ levels (Chivers et al., 2014; Munday et al., 2010), has been recently questioned (Clark et al., 2020). Similarly, the great dilution effect occurring in oceans makes behavior effects from anthropogenic contaminants less likely in marine ecosystems. Yet, large-scale anthropogenic forcing on fish boldness is expected in oceans due to the impacts from acoustic stressors and fishery (Fig. 1), even if hypoxia (Thambithurai et al., 2019) and marine protected areas (Gilman et al., 2019) may work counteractive to selective harvesting of fish behavior type by fisheries. Recent empirical studies show that it is behavioral traits rather than body size per se that determines fish's vulnerability for being harvested during fishery (Biro \& Post, 2008), and that selection response of behavioral trait is faster than that of life-history traits (Merilä \& Sheldon, 2000; Mousseau \& Roff, 1987). These studies imply that natural selection on behavioral traits is driving populations towards populations with more shy behaviors (Uusi-Heikkilä et al., 2008). So far, models probing how fishery induced changes in fish population behavior have focused on evolutionary effects (Andersen et al., 2018; Arlinghuas et al., 2015; Uusi-Heikkilä et al., 2015; Wolf et al., 2007) and our work is the first theoretical attempt to explore ecosystem-level consequences of such anthropogenic forcing. With an ecosystem perspective in mind, our findings suggest that reductions in boldness due to fishery induced selection pressure can cause nonlinear ecological transitions, induce regime shift and even threaten the existence of predator species.

The classic prediction in the context of fisheries-induced evolution is that boldness change brings out the reduction in maximally attainable body size (Laugen et al., 2014) is well supported by our modelling result (Fig. 4b). The reduction in maximal size is due to the slowed growth rate as a consequence of shy fishes foraging at slower rates (Fig. 5b). The driver of boldness reduction in the context of fisheries is that passive gears favor shy individuals with a lower feeding activity (for empirical evidence see Philipp et al., 2015; Tsuboi et al., 2015; Alós et al., 2016). Importantly, our model prediction is based on the assumption that boldness increases only for juvenile consumers, but the conclusion remains qualitatively valid even if boldness increases for all consumer individuals (Appendix S4). Recently, a theoretical study in a context of fisheries-induced evolution predicted that there is no clear correlation between boldness alteration 
and the maximal adult size (Andersen et al., 2018). This model lacked density dependent regulation of growth, which we showed to be the driver of change in maximum size. However, the two models agree in their predictions of reduced boldness and growth.

Taken together, boldness change could have a great potential to affect population recruitment, life history, and ecosystem structure in both freshwater and marine ecosystems. While these findings were drawn from a study of the zooplankton-roach-perch system, they apply generally to other important ecosystems based on copepod-forage fish-predatory fish food chains, such as the Barents and Baltic seas (Lindegren et al., 2010). A common feature of these systems is that they are typical tri-trophic fish systems in similarity to our model and have relatively simple population interactions. For species rich ecosystems with complex population interactions, network-based food web models (Loeuille \& Loreau, 2005; Schneider et al., 2016) or fishery-oriented Ecosim models (Walters et al., 1997, 2000) could be adopted to explore the scaled-up effects of individual-level boldness changes. However, neither of the two model types fully account for individual ontogenetic development as we did here for the consumer species. Fortunately, the recently developed size-structured food web models (Hartvig et al., 2011; Hartvig \& Andersen, 2013), may serve as a promising solution for future studies. In addition, unlike previous studies with adaptive change in behavior traits to optimize fitness proxy (e.g. Kondoh, 2003; Genkai-Kato, 2007), boldness trait in our model is purely driven by the external environment. Nevertheless, our model represents the first population model that is driven by a shift in fish boldness, and the model output should be viewed as explorative for other ecosystems as species may show asymmetrical behavioral responses to anthropogenic stressors (Brodin et al., 2014).

Our model provides a first road map into ecosystem structure effects that are expected to accompany anthropogenic stressors acting on fish population and thus, could be used to either validate or invalidate theories suggesting that altered fish boldness results in ecosystem change. Currently, the use of non-lethal (behavioral) response within ecotoxicological research is questioned due to the difficulties in interpreting their relevance (Johnson et al., 2020) - a knowledge gap that our model now confronts. However, while studies have provided promising 
findings linking fish boldness scores in laboratory settings to behavior in the wild, the importance of long-term changes in behavior repertoires due to learning or behavioral plasticity remains a challenge when extrapolating laboratory findings to nature (Fahlman et al., 2020). Indeed, behavioral plasticity and learning may dampen the effects of anthropogenic induced boldness; hence, there is a need of future studies assessing the persistence of fish behavioral traits in natural settings. Moreover, our model indicates that important ecosystem variables such as biomass of juveniles is fairly resilient to the minor $(\sim 0.1)$ shift in $\Delta \tau$ (Fig. 3), i.e. a change typically seen in response to exposure to more environmental relevant concentrations of chemical stressors (Fig. 2). In other words, our model suggests that previous concern for devastating impacts on juvenile fish populations due to minor chemically induced shift in boldness might be unjustified. However, we argue that long-term and multi-trophic mesocosm experiments (Nagelkerken \& Munday, 2015), harboring zooplankon, roach and perch, are needed to fully rule out important effects on juvenile populations due to chemical stressors cause minor $(\Delta \tau \leq 0.1)$ changes in fish boldness. Here, studies bridging the gaps between short-term behavior assays and more long-term behavior in more complex natural settings seem urgently needed.

\section{Conclusion}

While the research on how anthropogenic stressors affect individual fish behavior is still at an early stage, the near omnipresence of these stressors in oceans and freshwater ecosystems is of concern. Our modelling offers the first insights into ecosystem structure changes that can occur in a three trophic level aquatic ecosystem due to changes in fish boldness, and thus, represents a road map for scientists and policymakers searching for ecosystem effects caused by anthropogenic forcing of fish behavior. What is clear from our modelling efforts is that anthropogenic forcing on boldness traits, if expressed in nature, may cause recruitment and life-history traits effects. It seems evident that these effects are dependent on the strength of the stressor, where on the boldness-shyness continuum changes occurs as well on species-specific life-stages. Hence, anthropogenic forcing on fish boldness traits seem to represent one malicious driver of environmental change as it can be a hidden mechanism behind some of the ongoing 
ecosystem changes observed in aquatic ecosystems.

This article is protected by copyright. All rights reserved 


\section{Acknowledgments}

LZ acknowledges the financial support by the PRC Grant NSFC (11871065), the National Key Research and Development Program of China (2018YFE0109600), the NSF of Jiangsu Province (BK20181450), the Jiangsu Distinguished Processor Program, and the Yangzhou Talent Program 'LvYangJinFeng'. KHA is supported by the Villum Centre of Excellence “Ocean Life".

None of the authors have a conflict of interest to declare.

\section{Author contributions}

JK and LZ designed the study. LZ, KHA and NX developed the model. LZ and WW performed numerical simulations and analysis, empirical data collection and analysis. JK, LZ and NX wrote the manuscript draft with input from KHA. All authors contributed to the discussion of the results and the final text.

\section{Data availability statement}

Data sharing not applicable to this article as no new data were created or analyzed in this study. 


\section{References}

Adriaenssens, B., \& Johnsson, J. I. (2011). Shy trout grow faster: exploring links between personality and fitness-related traits in the wild. Behavioral Ecology, 22, 135-143.

Alós, J., Palmer, M., Rosselló, R., \& Arlinghaus, R. (2016). Fast and behavior-selective exploitation of a marine fish targeted by anglers. Scientific Reports, 6, 38093.

Andersen, K. H., Marty, L., \& Arlinghaus, R. (2018). Evolution of boldness and life history in response to selective harvesting. Canadian Journal of Fisheries and Aquatic Sciences, 75, $271-281$

Appelberg, M., Henrikson, B. I., Henrikson, L., \& Svedäng, M. (1993). Biotic interactions within the littoral community of swedish forest lakes during acidification. Ambio, 22, 290-297.

Arlinghaus, R., Alós, J., Klefoth, T., Laskowski, K., Monk, C. T., Nakayama, S., \& Schröder, A. (2015). Consumptive tourism causes timidity, rather than boldness, syndromes: a response to Geffroy et al. Trends in ecology \& evolution, 31, 92-94.

Arlinghaus, R., Laskowski, K. L., Alós, J., Klefoth, T., Monk, C. T., Nakayama, S., \& Schröder, A. (2017). Passive gear-induced timidity syndrome in wild fish populations and its potential ecological and managerial implications. Fish and Fisheries, 18, 360-373.

Biro, P. A., Beckmann, C., \& Stamps, J. A. (2010). Small within-day increases in temperature affects boldness and alters personality in coral reef fish. Proceedings of the Royal Society B: Biological Sciences, 277, 71-77.

Biro, P. A., \& Post, J. R. (2008). Rapid depletion of genotypes with fast growth and bold personality traits from harvested fish populations. Proceedings of the National Academy of Sciences, 105, 2919-2922.

Biro, P. A., \& Stamps, J. A. (2008). Are animal personality traits linked to life-history productivity? Trends in Ecology \& Evolution, 23, 361-368.

Briffa, M., Bridger, D., \& Biro, P. A. (2013). How does temperature affect behaviour? Multilevel analysis of plasticity, personality and predictability in hermit crabs. Animal behaviour, 86, 47-54.

This article is protected by copyright. All rights reserved 
Brodin, T., Fick, J., Jonsson, M., \& Klaminder, J. (2013). Dilute concentrations of a psychiatric drug alter behavior of fish from natural populations. Science, 339, 814-815.

Brodin, T., Nordling, J., Lagesson, A., Klaminder, J., Hellström, G., Christensen, B., \& Fick, J. (2017). Environmental relevant levels of a benzodiazepine (oxazepam) alters important behavioral traits in a common planktivorous fish (Rutilus rutilus). Journal of Toxicology and Environmental Health, Part A, 80, 1-8.

Brodin, T., Piovano, S., Fick, J., Klaminder, J., \& Jonsson, M. (2014). Ecological effects of pharmaceuticals in aquatic systems - impacts through behavioural alterations. Philosophical Transactions of The Royal Society B Biological Sciences, 369, 20130580.

Brown, G. E., Elvidge, C. K., Ferrari, M. C., \& Chivers, D. P. (2012). Understanding the importance of episodic acidification on fish predator-prey interactions: does weak acidification impair predator recognition? Science of the Total Environment, 439, 62-66.

Chivers, D. P., McCormick, M. I., Nilsson, G. E., Munday, P. L., Watson, S. A., Meekan, M. G., Mitchell, M. D., Corkill, K. C., \& Ferrari, M. C. O. (2014). Impaired learning of predators and lower prey survival under elevated $\mathrm{CO}_{2}$ : a consequence of neurotransmitter interference. Global Change Biology, 20, 515-522.

Claessen, D., \& de Roos, A. M. (2003). Bistability in a size-structured population model of cannibalistic fish-a continuation study. Theoretical Population Biology, 64, 49-65.

Clark, T. D., Raby, G. D., \& Roche, D. G. (2020). Ocean acidification does not impair the behaviour of coral reef fishes. Nature, 577, 370-375.

de Roos, A. M., \& Persson, L. (2002). Size-dependent lifer-history traits promote catastrophic collapses of top predators. Proceedings of the National Academy of Sciences USA, 99, 12907-12912.

de Roos, A. M., \& Persson, L. (2001). Physiologically structured models-from versatile technique to ecological theory. Oikos, 94, 51-71.

Dzieweczynski, T. L., Kane, J. L., Campbell, B. A., \& Lavin, L. E. (2016). Fluoxetine exposure impacts boldness in female Siamese fighting fish, Betta splendens. Ecotoxicology, 25, 69-79.

This article is protected by copyright. All rights reserved 
Dzieweczynski, T. L., Portrais, K. B., Stevens, M. A., Kane, J. L., \& Lawrence, J. M. (2018). Risky business: changes in boldness behavior in male siamese fighting fish, Betta splendens, following exposure to an antiandrogen. Environmental Pollution, 235, 1015-1021.

Fahlman, J., Hellström, G., Jonsson, M., Veenstra, A., \& Klaminder, J. (2020). Six common behavioral trials and their relevance for perch performance in natural lakes. Science of The Total Environment, 732, 139101.

Genkai-Kato, M. (2007). Macrophte refuges, prey behaviour and trophic interactions: consequences for lake water clarity. Ecology Letters, 10, 105-114.

Gilman, E., Kaiser, M. J., \& Chaloupka, M. (2019). Do static and dynamic marine protected areas that restrict pelagic fishing achieve ecological objectives? Ecosphere, 10, e02968.

Härkönen, L., Hyvärinen, P., Niemelä, P. T., \& Vainikka, A. (2016). Behavioural variation in Eurasian perch populations with respect to relative catchability. Acta Ethologica, 19, 21-31.

Härkönen, L., Hyvärinen, P., Paappanen, J., \& Vainikka, A. (2014). Explorative behavior increases vulnerability to angling in hatchery-reared brown trout Salmo trutta. Canadian Journal of Fisheries and Aquatic Sciences, 71, 1900-1909

Hartvig, M., Andersen, K. H., \& Beyer, J. E. (2011). Food web framework for size-structured populations. Journal of theoretical biology, 272, 113-22.

Hartvig, M., \& Andersen, K. H. (2013). Coexistence of structured populations with size-based prey selection. Theoretical population biology, 89, 24-33.

Jackson, C. D., \& Brown, G. E. (2011). Differences in antipredator behaviour between wild and hatchery-reared juvenile Atlantic salmon (Salmo salar) under seminatural conditions. Canadian Journal of Fisheries and Aquatic Sciences, 68, 2157-2166.

Johnson, A. C., Jin, X., Nakada, N., \& Sumpter, J. P. (2020). Learning from the past and considering the future of chemicals in the environment. Science, 367, 384-387.

Jørgensen, C., \& Holt, R. E. (2013). Natural mortality: its ecology, how it shapes fish life histories, and why it may be increased by fishing. Journal of Sea Research, 75, 8-18.

This article is protected by copyright. All rights reserved 
Klaminder, J., Jonsson, M., Leander, J., Fahlman, J., Brodin, T., Fick, J., \& Hellstrom, G. (2019). Less anxious salmon smolt become easy prey during downstream migration. Science of the total environment, 687, 488-493.

Klaminder, J., Jonsson, M., Fick, J., Sundelin, A., \& Brodin, T. (2014). The conceptual imperfection of aquatic risk assessment tests: highlighting the need for tests designed to detect therapeutic effects of pharmaceutical contaminants. Environmental Research Letters, 9, 084003.

Kondoh, M. (2003). Foraging adaptation and the relationship between food web complexity and stability. Science, 299, 1388-1391.

Kooijman, S. A. L. M. (1993). Dynamic Energy Budgets in Biological Systems, 1st Edition. Cambridge University Press, Cambridge, UK.

Lagesson, A., Brodin, T., Fahlman, J., Fick, J., \& Klaminder, J. (2018a). No evidence of increased growth or mortality in fish exposed to oxazepam in semi-natural ecosystems. Science of The Total Environment, 615, 608-614.

Lagesson, A., Saaristo, M., Brodin, T., Fick, J., Kiaminder, J., Martin, J. M., \& Wong, B. B. M. (2018b). Fish on steroids: Temperature-dependent effects of $17 \beta$-trenbolone on predator escape, boldness, and exploratory behaviors. Environmental Pollution, 245, 243-252.

Lappalainen, A., Rask, M., \& Vuorinen, P. J. (1988). Acidification affects the perch, Perca fluviatilis, populations in small lakes, of southern Finland. Environmental biology of fishes, 21, 231-239.

Laugen, A. T., Engelhard, G. H., Whitlock, R., Arlinghaus, R., Dankel, D. J., Dunlop, E. S., Eikeset, A. M., Enberg, K., Jørgensen, C., Matsumura, S., Nusslé, S., Urbach, D., Baulier, L., Boukal, D. S., Ernande, B., Johnston, F. D., Mollet, F., Pardoe, H., Therkildsen, N. O., Uusi-Heikkilä, S., Vainikka, A., Heino, M., Rijnsdorp, A. D., \& Dieckmann, U. (2014). Evolutionary impact assessment: accounting for evolutionary consequences of fishing in an ecosystem approach to fisheries management. Fish and Fisheries, 15, 65-96.

This article is protected by copyright. All rights reserved 
Loeuille, N., \& Loreau, M. (2005). Evolutionary emergence of size-structured food webs. Proceedings of the National Academy Sciences of the United States of American, 102, 5761-5766.

Lind, J., \& Cresswell, W. (2005) Determining the fitness consequences of antipredation behavior. Behavioral Ecology, 16, 945-956.

Lindegren, M., Möllmann, C., Nielsen, A., Brander, K., Mackenzie, B. R., \& Stenseth, N. C. (2010). Ecological forecasting under climate change: The case of Baltic cod. Proceedings of the Royal Society B: Biological Sciences, 277, 2121-2130.

Magnhagen, C., \& Borcherding, J. (2008). Risk-taking behaviour in foraging perch: does predation pressure influence age-specific boldness? Animal Behaviour, 75, 509-517.

McCormick, M. I., Allan, B. J. M., Harding, H., \& Simpson, S. D. (2018). Boat noise impacts risk assessment in a coral reef fish but effects depend on engine type. Scientific Reports, 8, 3847.

McCormick, M. I., Chivers, D. P., Ferrari, M. C. O., Blandford, M. I., Nanninga, G. B., Richardson, C., Fakan, E. P., Vamvounis, G., Gulizia, A.M., \& Allan, B. J. M. (2020). Microplastic exposure interacts with habitat degradation to affect behaviour and survival of juvenile fish in the field. Proceedings of the Royal Society of London: Biological Science, $287,20201947$.

Merilä, J., \& Sheldon, B. C. (2000). Lifetime reproductive success and heritability in nature. The American Naturalist, 155, 301-310.

Mills, S. C., Beldade, R., Henry, L., Laverty, D., Nedelec, S. L., Simpson, S. D., \& Radford, A. N. (2020). Hormonal and behavioural effects of motorboat noise on wild coral reef fish. Environmental Pollution, 262, 114250.

Mousseau, T. A., \& Roff, D. A. (1987). Natural selection and the heritability of fitness components. Heredity, 59, 181-197.

Munday, P. L., Dixson, D. L., McCormick, M. I., Meekan, M., Ferrari, M. C., \& Chivers, D. P. (2010). Replenishment of fish populations is threatened by ocean acidification. Proceedings of the National Academy of Sciences, 107, 12930-12934.

This article is protected by copyright. All rights reserved 
Muniz, I. P. (1984). The effects of acidification on Scandinavian freshwater fish fauna. Philosophical Transactions of the Royal Society of London. B, Biological Sciences, 305, 517-528.

Nagelkerken, I., \& Munday, P. (2015). Animal behaviour shapes the ecological effects of ocean acidification and warming: Moving from individual to community-level responses. Global change biology, 22, 13167.

Nedelec, S. L., Mills, S. C., Radford, A. N., Beldade, R., Simpson, S. D., Nedelec, B., \& Côté, I. M. (2017). Motorboat noise disrupts cooperative interspecific interactions. Scientific Reports, $7,6987$.

Nilsson, G. E., Dixson, D. L., Domenici, P., McCormick, M. I., Sorensen, C., Watson, S. A., \& Munday, P. L. (2012). Near-future carbon dioxide levels alter fish behaviour by interfering with neurotransmitter function. Nature Climate Change, 2, 201-204.

Ou, M., Hamilton, T. J., Eom, J., Lyall, E. M., Gallup, J., Jiang, A., Lee, J., Close, D. A., Yun, S. S., \& Brauner, C. J. (2015). Responses of pink salmon to CO2-induced aquatic acidification. Nature Climate Change, 5, 950-955

Øverli, Ø., Sørensen, C., Kiessling, A., Pottinger, T. G., \& Gjøen, H. M. (2006). Selection for improved stress tolerance in rainbow trout (Oncorhynchus mykiss) leads to reduced feed waste. Aquaculture, 261, 776-781.

Philipp, D. P., Claussen, J. E., Koppelman, J., Stein, J. A., Cooke, S., Suski, C. D., Wahl, D. H., Sutter, D. A. H., \& Arlinghaus, R. (2015). Fisheries-Induced Evolution in Largemouth Bass: Linking Vulnerability to Angling, Parental Care, and Fitness. American Fisheries Society Symposium, 82, 223-234.

Réale, D., Garant, D., Humphries, M. M., Bergeron, P., Careau, V., \& Montiglio, P. O. (2010). Personality and the emergence of the pace-of-life syndrome concept at the population level. Philosophical Transactions of the Royal Society B: Biological Sciences, 365, 4051-4063.

Réale, D., Reader, S. M., Sol, D., McDougall, P. T., \& Dingemanse, N. J. (2007). Integrating animal temperament within ecology and evolution. Biological Reviews, 82, 291-318.

This article is protected by copyright. All rights reserved 
Roberts, L. J., Taylor, J., \&, Leaniz, C. G. D. (2011). Environmental enrichment reduces maladaptive risk-taking behavior in salmon reared for conservation. Biological Conservation, 144, 1972-1979.

Sabet, S. S., Neo, Y. Y., \& Slabbekoorn, H. (2015). The effect of temporal variation in sound exposure on swimming and foraging behaviour of captive zebrafish. Animal Behaviour, 107, 49-60.

Schneider, F. D., Brose, U., Rall, B. C., \& Guill, C. (2016). Animal diversity and ecosystem functioning in dynamic food webs. Nature Communications, 7, 12718.

Smith, B. R., \& Blumstein, D. T. (2008) Fitness consequences of personality: A meta-analysis. Behavioral Ecology, 19, 448-455.

Sprague, J. B. (1971). Measurement of pollutant toxicity to fish-III: Sublethal effects and "safe" concentrations. Water Research, 5, 245-266.

Tanoue, R., Margiotta-Casaluci, L., Huerta, B., Runnalls, T. J., Eguchi, A., Nomiyama, K., Kunisue, T., Tanabe, S., \& Sumpter, J. P. (2019). Protecting the environment from psychoactive drugs: Problems for regulators illustrated by the possible effects of tramadol on fish behaviour. Science of the Total Environment, 664, 915-926.

Thambithurai, D., Crespel, A., Norin, T., Rácz, A., Lindström, J., Parsons, K. J., \& Killen, S. S. (2019). Hypoxia alters vulnerability to capture and the potential for trait-based selection in a scaled-down trawl fishery. Conservation Physiology, 7, coz082.

Tsuboi, J. I., Morita, K., Klefoth, T., Endou, S., \& Arlinghaus, R. (2015). Behaviour-mediated alteration of positively size-dependent vulnerability to angling in response to historical fishing pressure in a freshwater salmonid. Canadian Journal of Fisheries and Aquatic Sciences, 73, 461-468.

Uusi-Heikkilä, S., Whiteley, A. R., Kuparinen, A., Matsumura, S., Venturelli, P. A., Wolter, C., Slate, J., Primmer, C. R., Meinelt, T., Killen, S. S., Bierbach, D., Polverino, G., Ludwig, A., \& Arlinghaus, R. (2015). The evolutionary legacy of size-selective harvesting extends from genes to populations. Evolutionary Applications, 8, 597-620.

This article is protected by copyright. All rights reserved 
Uusi-Heikkilä, S., Wolter, C., Klefoth, T., \& Arlinghaus, R. (2008). A behavioral perspective on fishing-induced evolution. Trends in ecology \& evolution, 23, 419-421.

Vignet, C., Joassard, L., Lyphout, L., Guionnet, T., Goubeau, M., Menach, K. L., Brion, F., Kah, O., Chung, B. C., Budzinski, H., Bégout, M. L., \& Cousin, X. (2015). Exposures of zebrafish through diet to three environmentally relevant mixtures of PAHs produce behavioral disruptions in unexposed F1 and F2 descendant. Environmental Science and Pollution Research, 22, 16371-16383.

Walsh, M. R., Munch, S. B., Chiba, S., \& Conover, D. O. (2006). Maladaptive changes in multiple traits caused by fishing: impediments to population recovery. Ecology letters, 9 , $142-148$

Walters, C., Christensen, V., \& Pauly, D. (1997). Structuring dynamic models of exploited ecosystems from trophic mass-balass assessments. Reviews in Fish Biology and Fisheries, 7, 139-172.

Walters, C., Pauly, D., Christensen, V., \& Kitchell, J. F. (2000). Representing density dependent consequences of life history strategies in aquatic ecosystems: Ecosim II. Ecosystems, 3, 70-83.

Ward, A. J., Thomas, P., Hart, P. J., \& Krause, J. (2004). Correlates of boldness in three-spined sticklebacks (Gasterosteus aculeatus). Behavioral Ecology and Sociobiology, 55, 561-568.

Wolf, M., van Doorn, G. S., Leimar, O., \& Weissing, F. J. (2007). Life-history trade-offs favour the evolution of animal personalities. Nature, 447, 581-584.

Wund, M. A., Baker, J. A., Golub, J. L., \& Foster, S. A. (2015). The evolution of antipredator behaviour following relaxed and reversed selection in Alaskan threespine stickleback fish. Animal behaviour, 106, 181-189.

Závorka, L., Koeck, B., Armstrong, T. A., Soğanci, M., Crespel, A., \& Killen, S. S. (2020). Reduced exploration capacity despite brain volume increase in warm acclimated common minnow. Journal of Experimental Biology, 223, 223453.

This article is protected by copyright. All rights reserved 
FIGURE 1 Anthropogenic forcing of fish behavior. Conceptual illustration shows how different chemical and fishery related stressors cause behavior changes along the boldness-shyness axis, where arrows indicate only direction of shift and not the strength of the shift. Here, the fish can become either bolder (and exploratory) or shyer (less willing to take risks) depending on stressors. While pharmaceutical contaminants (anxiolytics, anti-depressants and hormones) generally are believed to act via their therapeutic mode of action (Brodin et al., 2013; Dzieweczynski et al., 2016; Lagesson et al., 2018b), increased boldness in response to reduced $\mathrm{pH}$ is both caused by reduced ability to recognize predators cues at low pH-values (Brown et al., 2012) and direct $\mathrm{pH}$ impacts on the GABAa-receptor in the nervous system (Nilsson et al., 2012). Note that the importance of pH-driven behavior changes has recently been questioned (Clark et al., 2020). Increased boldness occurs also in response to elevated temperature as a consequence of energetic regulation on metabolism (Briffa et al., 2013) and to microplastics due to nutritional stress (McCormick et al., 2020). Fisheries modify the behavior of fish populations directly by selectively harvesting bold and exploratory individuals (Andersen et al., 2018; Arlinghaus et al., 2017), but also indirectly by generating acoustic emissions (McCormick et al., 2018; Sabet et al., 2015) and by stocking freshwater with bolder fish reared in hatcheries (Härkönen et al., 2014).

FIGURE 2 Examples of chemical chemical stressors that induced changes in boldness $(\tau)$ (a) and foraging rate (b) for fish in laboratory behavioral trials. Note that the experimental design differed between studies, where boldness scores were either measured as the time $\left(t_{1}\right)$ spent in an area with increased perceived risk (novel object inspection, scototaxis or movements outside the thigmotaxis zone) during the observational period ( $t$ ) or the inverse of latency $\left(\mathrm{t}_{2}\right)$ to enter such area, i.e. boldness is expressed in the figure as $t_{1} / t$ or $1-t_{2} / t$. Foraging rate was originally measured as the latency to capture the first $\left(10^{\text {th }}\right.$ and $\left.20^{\text {th }}\right)$ zooplankton, but rescaled here to the number of 
zooplanktons consumed by perch every 100 seconds. Boldness and foraging rate were computed under three states: the control (white) and the chemically elevated (light and dark gray) states with the numbers being the concentrations of the stressor compound. Numbers in bracket on the $x$-axis indicate the references where data were collected: [1] $\mathrm{CO}_{2}$-induced aquatic acidification on juvenile pink salmon (Ou et al., 2015); [2] psychiatric drug induced behavioral alteration in juvenile perch (Brodin et al., 2013); [3] benzodiazepine anxiolytic drug induced behavioral alteration in adult roach (Brodin et al., 2017); test of antiandrogens [4] and Fluoxetin [5] on boldness on adult Siamese fighting fish (Dzieweczynski et al., 2016, 2018); [6] effects of polycyclic aromatic hydrocarbons (PAHs) on two-month old juvenile zebrafish (Vignet et al., 2015). In addition, the numbers in bars indicate the concentrations of the corresponding chemical stressors. Boldness scores for control state (white bar) range between 0.12 to 0.78 with a mean value of $0.38 \pm 0.26( \pm$ std $)$. 
TABLE 1 Life history functions

\begin{tabular}{|c|c|c|}
\hline Interpretation & Function & Num \\
\hline Body mass & $w(x)=\beta x^{3}$ & N1 \\
\hline Vulnerable biomass & $B=\int_{x_{b}}^{x_{v}} w(x) c(t, x) d x$ & $\mathrm{~N} 2$ \\
\hline Digestion time & $H(x)=\xi_{1} w(x)^{\xi_{2}}$ & N3 \\
\hline Maintenance costs & $M(x)=\rho_{s} w(x)^{\rho_{1}}+\tau \rho_{f} w(x)^{\rho_{2}}$ & $\mathrm{~N} 4$ \\
\hline Attack rate & $A(x)=A_{\max }\left[\frac{w(x)}{w_{o p t}} \exp \left(1-\frac{w(x)}{w_{o p t}}\right)\right]^{\alpha}$ & N5 \\
\hline Food intake rate & $F(x, R)=\varepsilon_{R} \frac{\tau A(x) R}{1+\tau A(x) H(x) R}$ & N6 \\
\hline Growth rate in length & $g(x, R)=\left\{\begin{array}{cl}\frac{1}{3 \beta x^{2}}[\kappa F(x, R)-M(x)] & \text { if } \quad \kappa F(x, R) \geq M(x) \\
0 & \text { otherwise }\end{array}\right.$ & N7 \\
\hline Birth rate & $b(x, R)=\left\{\begin{array}{cc}c_{r}(1-\kappa) F(x, R) w\left(x_{b}\right)^{-1} & \text { if } x \geq x_{j} \\
0 & \text { otherwise }\end{array}\right.$ & N8 \\
\hline Mortality rate & $\mu(x, R, P)=\mu_{0}+\mu_{s}+\mu_{p}$ & N9 \\
\hline Starvation mortality & $\mu_{s}(x, R)=\left\{\begin{array}{cl}s[M(x)-\kappa F(x, R)] & \text { if } \quad \kappa F(x, R)<M(x) \\
0 & \text { otherwise }\end{array}\right.$ & N10 \\
\hline Predation mortality & $\mu_{P}=\frac{\tau a P}{1+\tau a T_{h} B}$ & N11 \\
\hline
\end{tabular}


TABLE 2 Model parameters

${ }^{1}$ de Roos \& Persson (2002), ${ }^{2}$ de Roos \& Persson (2001), ${ }^{3}$ Classen \& de Roos (2003),

\begin{tabular}{|c|c|c|c|}
\hline Symbols & Value & Unit & Interpretation \\
\hline$x_{b}$ & 7 & $\mathrm{~mm}$ & Length at birth ${ }^{1}$ \\
\hline$x_{v}$ & 27 & $\mathrm{~mm}$ & Maximal length vulnerable to predator ${ }^{1}$ \\
\hline$x_{j}$ & 110 & $\mathrm{~mm}$ & Length at maturation $^{1}$ \\
\hline$x_{m}$ & 300 & $\mathrm{~mm}$ & Maximal length $^{1}$ \\
\hline$\mu_{0}$ & 0.01 & $\mathrm{~d}^{-1}$ & Natural death rate ${ }^{1}$ \\
\hline$\beta$ & $9.0 \times 10^{-6}$ & $\mathrm{~g} \mathrm{~mm}^{-3}$ & Proportionality of length to body size ${ }^{1}$ \\
\hline$r$ & 0.1 & $\mathrm{~d}^{-1}$ & Intrinsic growth rate of resource ${ }^{1}$ \\
\hline$K$ & 0.0003 & g liter ${ }^{-1}$ & Resource carrying capacity ${ }^{4}$ \\
\hline$\varepsilon_{R}$ & 0.6 & - & Conversion efficiency ${ }^{3}$ \\
\hline$\varepsilon$ & 0.005 & - & Predator reproduction efficiency ${ }^{4}$ \\
\hline$a$ & $3.8 \times 10^{5}$ & liter $\mathrm{d}^{-1}$ & Attack rate of predator ${ }^{4}$ \\
\hline$T_{h}$ & 0.175 & $\mathrm{~d} \mathrm{~g}^{-1}$ & Handling time of Roach ${ }^{4}$ \\
\hline$\delta$ & 0.01 & $\mathrm{~d}^{-1}$ & Predator mortality ${ }^{1}$ \\
\hline$\xi_{1}$ & 5 & $\mathrm{~d} \mathrm{~g}^{-\left(1+\xi_{2}\right)}$ & Allometric constant in handing time function ${ }^{2}$ \\
\hline$\xi_{2}$ & -0.8 & - & Allometric exponent in handing time function ${ }^{2}$ \\
\hline$\rho_{1}$ & 0.77 & - & Allometric exponent in background metabolic cost $\mathrm{t}^{2}$ \\
\hline$\rho_{2}$ & 0.77 & - & Allometric exponent in active metabolic cost $\mathrm{t}^{5}$ \\
\hline$\rho_{s}$ & 0.033 & $\mathrm{~g}^{\left(1-\rho_{1}\right)} \mathrm{d}^{-1}$ & Allometric constant in background metabolic cost ${ }^{2}$ \\
\hline$\rho_{f}$ & 0.033 & $g^{\left(1-\rho_{2}\right)} d^{-1}$ & Allometric constant in active metabolic $\operatorname{cost}^{5}$ \\
\hline$\alpha$ & 0.6 & - & Allometric exponent in pelagic attack rate ${ }^{2}$ \\
\hline$A_{\max }$ & $1.5 \times 10^{5}$ & liter $\mathrm{d}^{-1}$ & Maximum pelagic attack rate ${ }^{2}$ \\
\hline$w_{\text {opt }}$ & 50 & $\mathrm{~g}$ & Body size with maximum pelagic attack rate ${ }^{2}$ \\
\hline$\kappa$ & 0.7 & - & Allocation coefficient ${ }^{3}$ \\
\hline$c_{r}$ & 0.5 & - & Efficiency of offspring reproduction ${ }^{3}$ \\
\hline$s$ & 1 & $\mathrm{~d}$ & Proportionality constant of starvation mortality ${ }^{1}$ rate \\
\hline
\end{tabular}

${ }^{4}$ Personal communication with de Roos, ${ }^{5}$ Default values taken the same as that of background metabolic costs. 
FIGURE 1 Anthropogenic forcing of fish behavior. Conceptual illustration shows how different chemical and fishery related stressors cause behavior changes along the boldness-shyness axis, where arrows indicate only direction of shift and not the strength of the shift. Here, the fish can become either bolder (and exploratory) or shyer (less willing to take risks) depending on stressors. While pharmaceutical contaminants (anxiolytics, anti-depressants and hormones) generally are believed to act via their therapeutic mode of action (Brodin et al., 2013; Dzieweczynski et al., 2016; Lagesson et al., 2018b), increased boldness in response to reduced $\mathrm{pH}$ is both caused by reduced ability to recognize predators cues at low $\mathrm{pH}$-values (Brown et al., 2012) and direct $\mathrm{pH}$ impacts on the GABAa-receptor in the nervous system (Nilsson et al., 2012). Note that the importance of $\mathrm{pH}$-driven behavior changes has recently been questioned (Clark et al., 2020). Increased boldness occurs also in response to elevated temperature as a consequence of energetic regulation on metabolism (Briffa et al., 2013) and to microplastics due to nutritional stress (McCormick et al., 2020). Fisheries modify the behavior of fish populations directly by selectively harvesting bold and exploratory individuals (Andersen et al., 2018; Arlinghaus et al., 2017), but also indirectly by generating acoustic emissions (McCormick et al., 2018; Sabet et al., 2015) and by stocking freshwater with bolder fish reared in hatcheries (Härkönen et al., 2014).

FIGURE 2 Examples of chemical chemical stressors that induced changes in boldness ( $\tau$ ) (a) and foraging rate (b) for fish in laboratory behavioral trials. Note that the experimental design differed between studies, where boldness scores were either measured as the time $\left(\mathrm{t}_{1}\right)$ spent in an area with increased perceived risk (novel object inspection, scototaxis or movements outside the thigmotaxis zone) during the observational period $(\mathrm{t})$ or the inverse of latency $\left(\mathrm{t}_{2}\right)$ to enter such area, i.e. boldness is expressed in the figure as $t_{1} / t$ or $1-t_{2} / t$. Foraging rate was originally measured as the latency to capture the first $\left(10^{\text {th }}\right.$ and $\left.20^{\text {th }}\right)$ zooplankton, but rescaled here to the number of zooplanktons consumed by perch every 100 seconds. Boldness and foraging rate were computed under three states: the control (white) and the chemically elevated (light and dark gray) states with the numbers being the concentrations of the stressor compound. Numbers in bracket on the $x$-axis indicate the references where data were collected: [1] $\mathrm{CO}_{2}$-induced aquatic acidification on juvenile pink salmon (Ou et al., 2015); [2] psychiatric drug induced behavioral alteration in juvenile perch (Brodin et al., 2013); [3] benzodiazepine anxiolytic drug induced behavioral alteration in adult roach (Brodin et al., 2017); test of antiandrogens [4] and Fluoxetin [5] on boldness on adult Siamese fighting fish (Dzieweczynski et al., 2016, 2018); [6] effects of polycyclic aromatic hydrocarbons (PAHs) on two-month old juvenile zebrafish (Vignet et al., 2015). In addition, the numbers in bars indicate the concentrations of the corresponding chemical stressors. Boldness scores for control state (white bar) range between 0.12 to 0.78 with a mean value of $0.38 \pm 0.26( \pm$ std). 
FIGURE 3 Equilibrium biomass of predator (a), juvenile (b) and adult consumers (c), and resource (d) for varied boldness $\tau$. Lines indicate stable (solid) and unstable (dashed) equilibria. Predator starts to coexist with the consumer and resource at $\tau^{*}$ indicated by the vertical dashed lines. Above the value $\tau^{*}, \tau$ is increased only for juvenile consumers. The shaded regions represent the boldness increment for the perch caused by increased concentration of oxazepam in the foraging experiment (Brodin et al., 2013) as shown in Fig. 2 b.

FIGURE 4 Consumer biomass (a) and body length (b) with increased boldness. The quantities were scaled with their respective values when three species start to coexist (i.e. $\tau=\tau^{*}$ ). Description of the shading regions is the same as in Fig. 3.

FIGURE 5 Reproduction (a) and growth rate (b) of consumer species with increased boldness. The reproduction was scaled with the value when the three species start to coexist (i.e. $\tau=\tau^{*}$ ).

\section{Supporting information}

Additional supporting information may be found online in the Supporting information section at the end of the article.

\section{Graphical abstract}

Modified fish behaviors in response to anthropogenic stressors, such as chemicals, microplastics, acoustic emissions and fisheries, are a debated driver of change in freshwater ecosystems and oceans. Here we show that anthropogenic stressors affecting fish boldness, are not expected to cause fish population collapse, but rather elusive effects on fish length, population biomass, reproduction and ecosystem state shifts. We conclude that anthropogenic forcing of fish behavior may be a hidden mechanism behind ecosystem structure changes in both freshwater and marine ecosystems. 


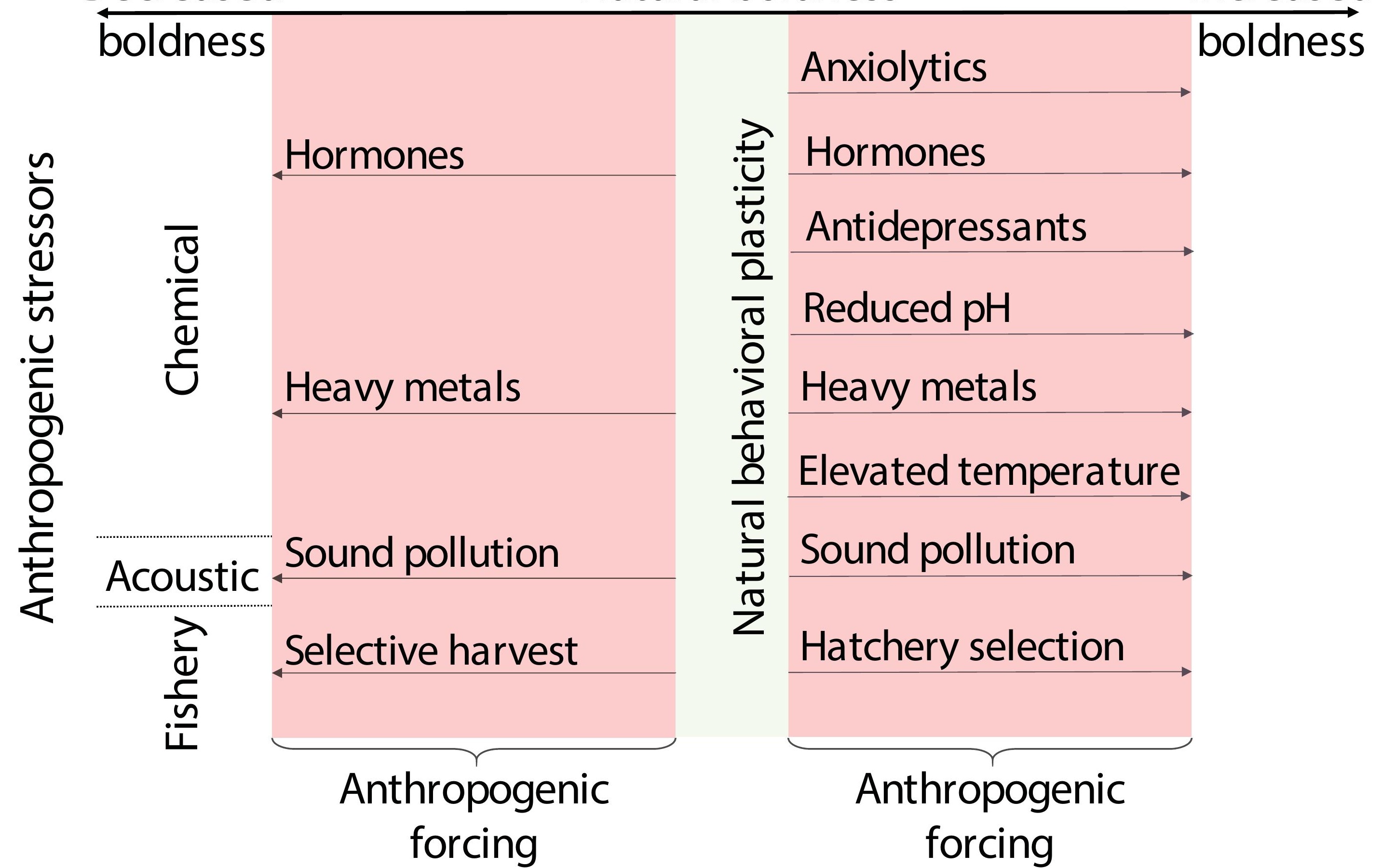




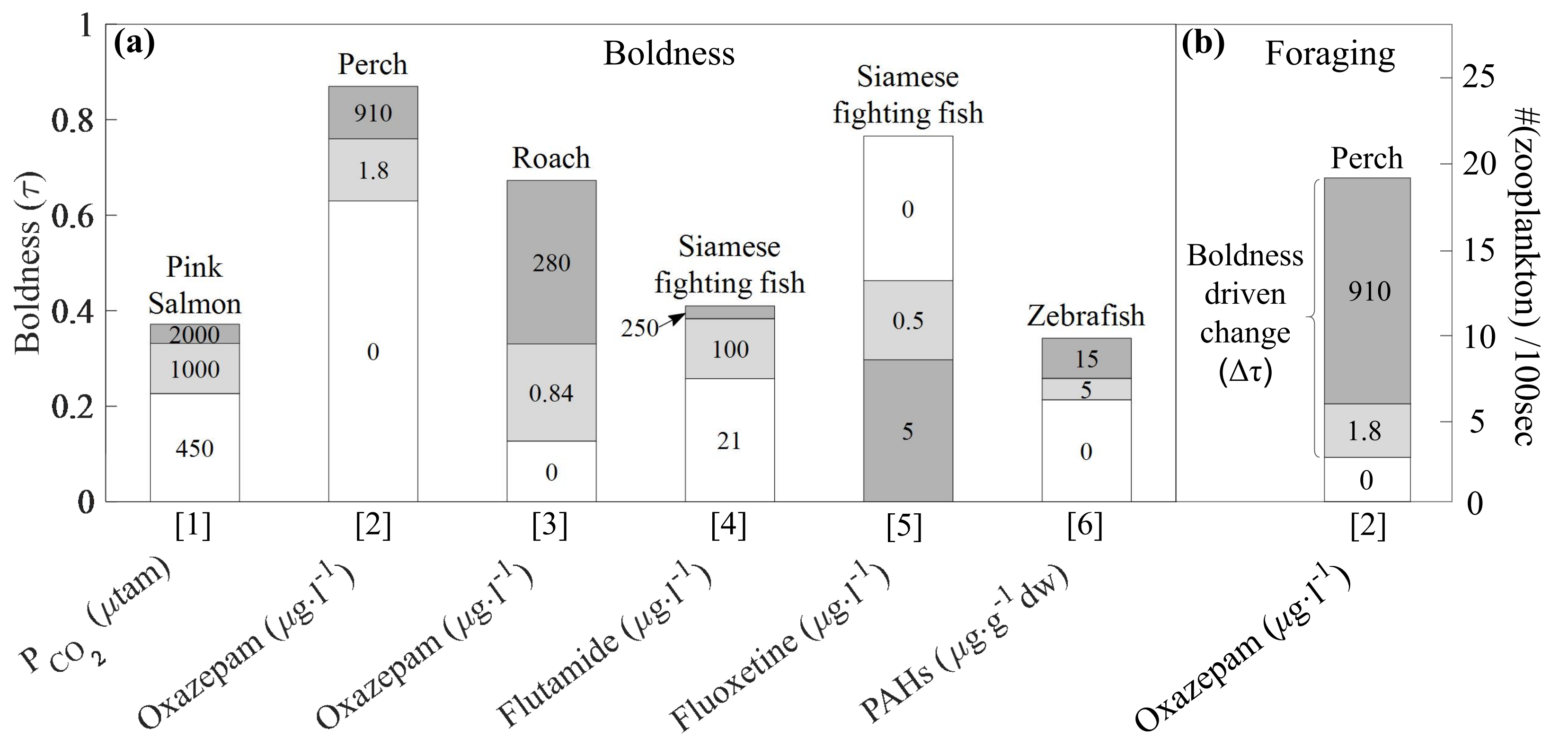




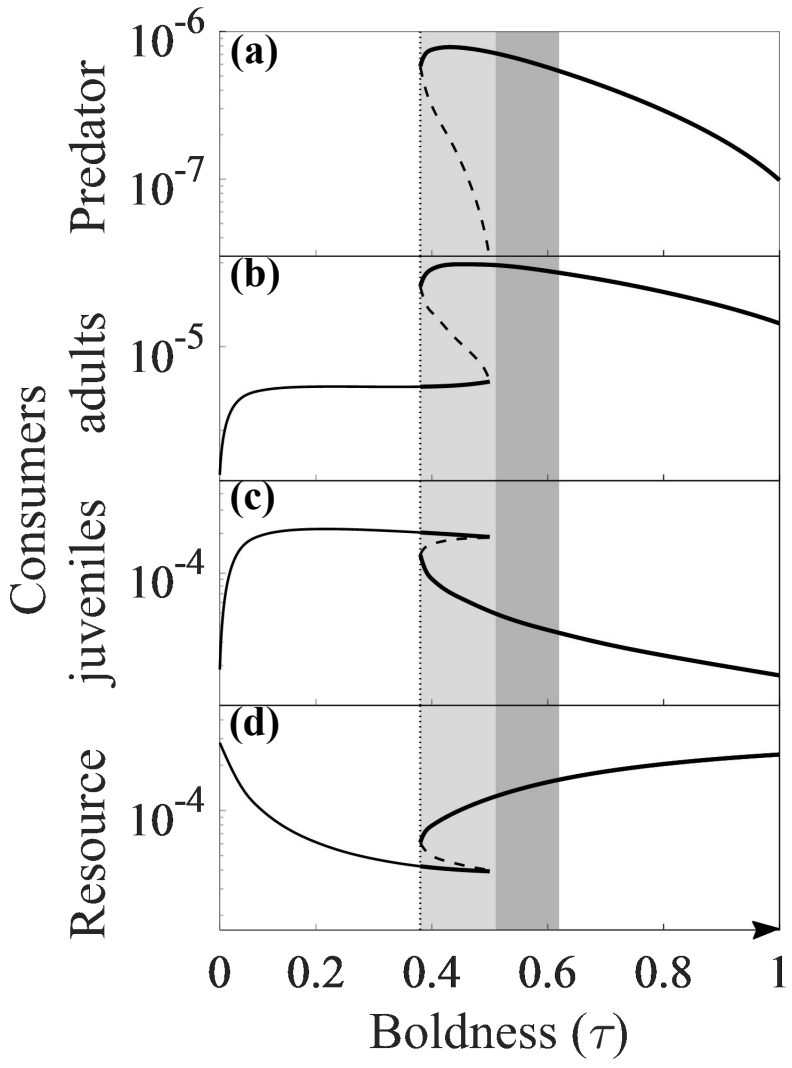




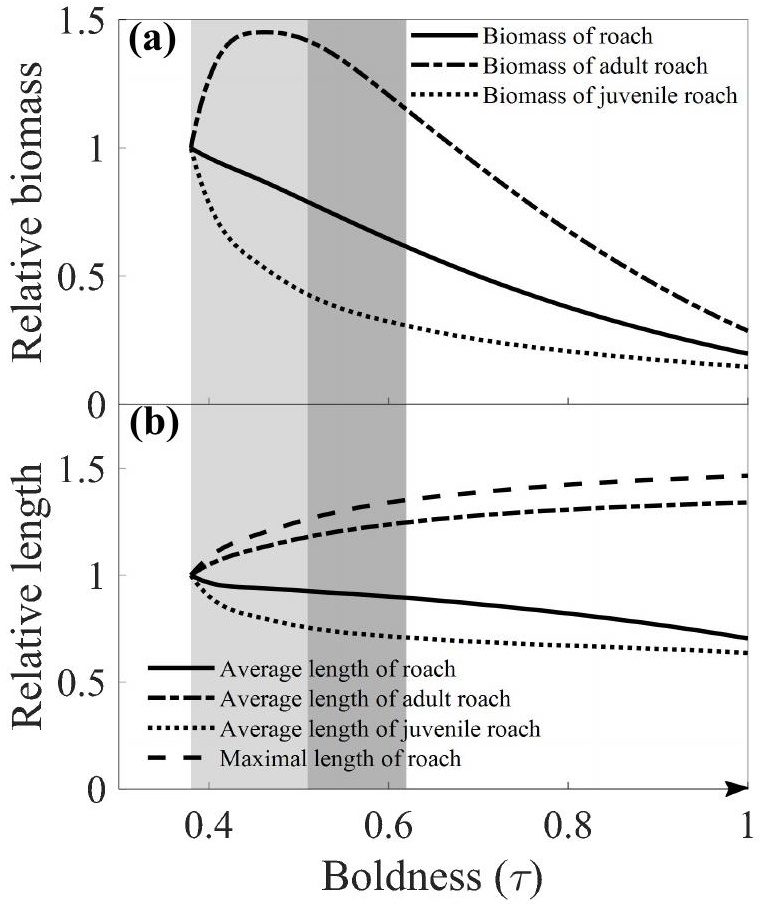



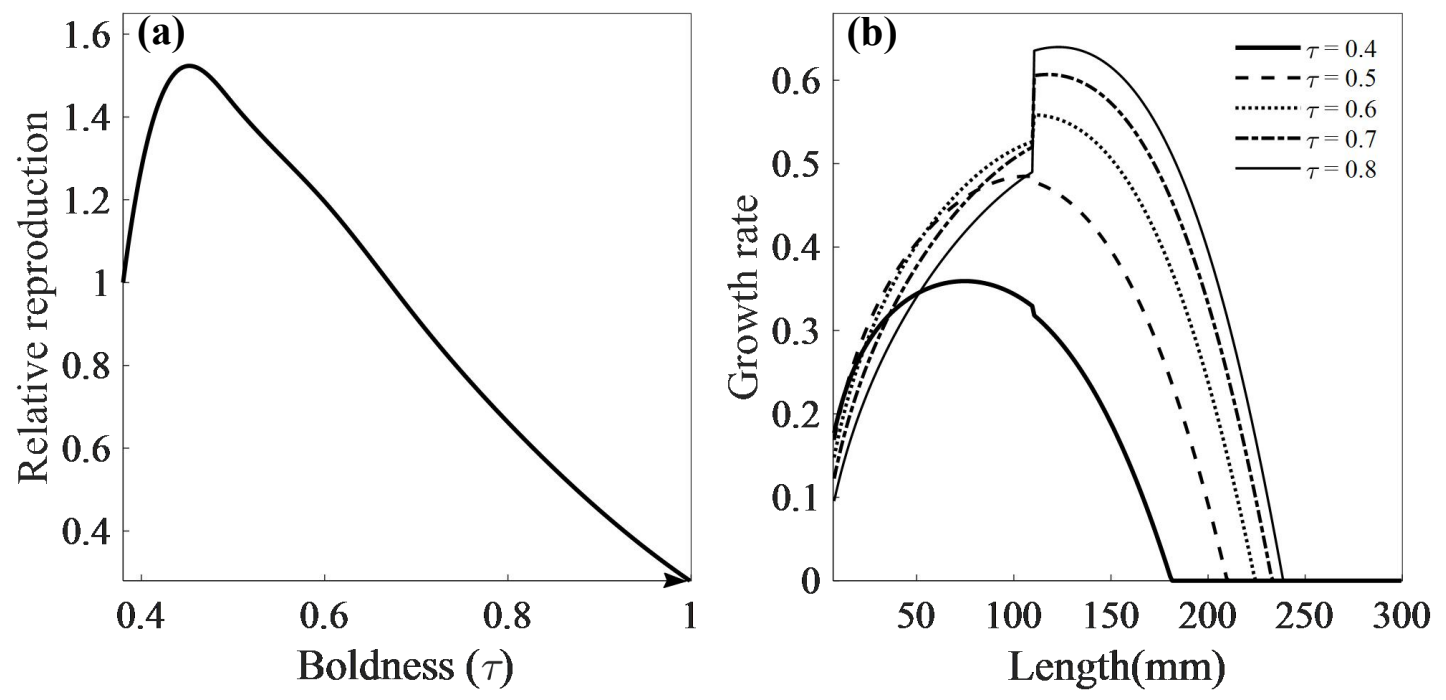